\title{
Faktor-faktor yang Mempengaruhi Keselarasan Strategi Teknologi Informasi dan Bisnis pada Pendidikan Tinggi
}

\author{
Tegar Alami \\ Program Studi Magister Teknik Informatika Pascasarjana Fakultas Teknologi Industri \\ Universitas Islam Indonesia \\ Jl. Kaliurang km 14.5, Sleman, Yogyakarta \\ e-mail: 15917123@students.uii.ac.id
}

\begin{abstract}
Abstrak
Keselarasan strategi Teknologi Informasi (TI) dan Bisnis adalah kunci utama yang menghubungkan antara harapan implementasi TI dengan pencapaian visi, misi dan keunggulan kompetitif yang berkesinambungan pada sebuah organisasi. Pada lembaga Pendidikan Tinggi, Keselarasan strategi TI dan Bisnis berperan sebagai aspek terpenting dalam mendukung efisiensi dan efektivitas proses pendidikan, penelitian, administrasi, dan pengabdian kepada masyarakat. kegagalan dalam menyelaraskan strategi TI dan bisnis akan mengakibatkan biaya investasi lebih tinggi dibandingkan perencanaan, posisi Keunggulan kompetitif universitas menjadi menurun, serta kegagalan dalam melakukan inovasi secara cepat. Penelitian ini bertujuan untuk mengidentifikasi faktor-faktor yang berpengaruh signifikan dalam mewujudkan kondisi strategi TI dan bisnis yang selaras pada level pendidikan tinggi. Faktor-faktor tersebut adalah berupa komitmen manajemen puncak, penggunaan tenaga TI eksternal, kemampuan staf TI internal, fleksibilitas infrastruktur TI, dan komunikasi pengetahuan antara eksekutif TI dan eksekutif bisnis. Berdasarkan hasil penelitian, maka dapat disimpulkan bahwa komitmen manajemen puncak, penggunaan tenaga TI eksternal, kemampuan staf TI internal, dan komunikasi pengetahuan antara eksekutif TI dan eksekutif bisnis berpengaruh signifikan terhadap keselarasan TI dan bisnis pada Universitas XYZ. Sedangkan untuk fleksibilitas infrastruktur TI tidak berpengaruh signifikan terhadap keselarasan TI dan bisnis pada Universitas XYZ. Dengan meningkatkan intensitas dan kualitas faktor-faktor yang berpengaruh signifikan terhadap keselarasan TI dan bisnis tersebut, maka diharapkan Universitas XYZ dapat menyelaraskan strategi TI dan bisnis sebagai penopang dalam pencapaian visi dan misi Universitas.
\end{abstract}

Kata kunci: Business IT Alignment, Perguruan Tinggi, Tata Kelola TI, Keselarasan Strategi TI dan Strategi Bisnis, Faktor-Faktor Keselarasan

\begin{abstract}
Strategic alignment of business-IT is the key to linking the expectations of IT implementation with achieving vision, mission and sustainable competitive advantage in an organization. In Higher Education institutions, alignment of strategic IT businesses is the most important aspect in supporting the efficiency and effectiveness of education, research, administration and public services. failure in strategic alignment will cause investment costs to be higher than planned expectations, university competitive advantage diminishes, and failure to innovate quickly. This study aims to identify the factors that influence IT alignment and business strategies that will provide a conceptual model in realizing IT conditions and business strategies that are aligned at the higher education level. These factors are the commitment of top management, the use of external IT personnel, the ability of internal IT staff, the use of IT infrastructure, and knowledge communication between IT executives and business executives. Based on the results of this study, it can be concluded that top management commitment, the use of external IT personnel, the ability of internal IT staff, and knowledge communication between
\end{abstract}


IT executives and business executives significantly affect the alignment of IT and business at $X Y Z$ University. As for the flexibility of IT infrastructure there is no need to be significant in aligning IT and business at XYZ University. By increasing the intensity and quality of factors that significantly affect IT and business alignment, it is hoped that XYZ University can align IT and business strategies as support in achieving the University's vision and mission.

Keywords: Business IT Alignment, Higher Education, IT Governance, Alignment of Business Strategies and IT Strategies, Alignment Factors.

\section{Pendahuluan}

Tata Kelola Teknologi Informasi adalah praktik yang sangat penting untuk meraih kesuksesan implementasi Teknologi Informasi (TI) di dalam pencapaian strategi sebuah organisasi [1]. Dalam menjalankan strategi, sebuah perusahaan memerlukan Tata Kelola TI sebagai dasar yang menghubungkan dan menyelaraskan sumberdaya TI, proses-proses TI, serta berbagai informasi yang dibutuhkan untuk mencapai target-target yang telah ditentukan. Tata kelola TI merupakan tanggung jawab eksekutif dan dewan direksi, yang terdiri dari kepemimpinan, struktur organisasi, dan proses yang memastikan bahwa TI di dalam sebuah organisasi dapat mendukung dan memperluas strategi dan tujuan organisasi [2].

Tata Kelola TI memiliki lima (5) fokus area, yaitu Strategic Alignment, Resource Management, Performance Measurement, Value Delivery dan Risk Management [2]. Dari lima (5) fokus area tersebut yang menjadi kunci utama untuk mencapai kesuksesan Tata Kelola TI di dalam sebuah organisasi adalah Strategic Alignment [2]. Sebab Keselarasan strategi TI dan bisnis memiliki peran penting yang dapat menghubungkan antara harapan penerapan TI dengan pencapaian visi, misi dan keberlangsungan hidup suatu organisasi serta memastikan bahwa TI memberikan kontribusi secara efektif terhadap pencapaian tujuan strategis organisasi [2]. Keselarasan strategi TI dan bisnis mampu mengoptimalkan pemanfaatan TI dalam sebuah organisasi untuk meningkatkan kinerja dan mengembangkan keunggulan kompetitif yang berkelanjutan [3] dan merupakan prinsip dasar dalam mencapai keunggulan kompetitif yang telah direkomendasikan lebih dari satu dekade [4].

Berbagai literatur telah memberikan bukti empiris bahwa keselarasan strategi bisnis dan TI sangat mempengaruhi kualitas Tata Kelola TI di dalam sebuah organisasi. Keselarasan antara strategi bisnis dan TI menyebabkan kualitas implementasi TI menjadi lebih efektif serta mendukung kinerja yang lebih tinggi pada perusahaan-perusahaan berskala kecil dan menengah di Kanada [5]. Penelitian lainnya [6] mengevaluasi hasil kinerja bisnis dalam menyelaraskan kompetensi sistem informasi dan strategi bisnis perusahaan-perusahaan di Kanada dengan menggunakan kuesioner yang ditujukan kepada 104 CEO dari perusahaan di Kanada. Hasil penelitian tersebut mengkonfirmasi bahwa keselarasan antara sistem informasi dan strategi bisnis secara signifikan meningkatkan kualitas Tata Kelola TI dan kinerja bisnis. Konsep Keselarasan strategi TI dan bisnis menyiratkan adanya hubungan yang strategis antara strategi bisnis dan Sistem Informasi untuk kebutuhan organisasi dan pengembangan organisasi [6] .

Sementara itu, ketidak hadiran Keselarasan strategi TI dan bisnis dalam sebuah organisasi akan menyebabkan Return of Investment TI tidak efisien, sehingga menyebabkan biaya lebih tinggi dibandingkan harapan yang telah direncanakan [7]. Strategi TI yang tidak selaras dengan strategi bisnis akan membawa perusahaan maupun industri pada kegagalan dalam melakukan inovasi secara cepat [8]. Keterlambatan dalam melakukan inovasi yang disebabkan oleh keselarasan yang buruk menyebabkan posisi Keunggulan kompetitif perusahaan menjadi menurun [9].

Keselarasan strategi TI dan bisnis menjadi perhatian tidak hanya untuk organisasi komersial saja, dalam sebuah organisasi non-profit, peran strategi TI yang dimaksud adalah meningkatkan efisiensi dalam pelaksanaan pekerjaan dan meningkatkan kinerja dalam melakukan aktivitas pelayanan. Seperti pada lembaga Pendidikan Tinggi, Keselarasan strategi TI dan bisnis perlu diterapkan mengingat bahwa TI pada Perguruan Tinggi pada era digital ini 
berperan sebagai aspek terpenting dalam mendukung efisiensi dan efektivitas proses pendidikan, penelitian, administrasi, dan pengabdian kepada masyarakat [10]. Oleh sebab itu Keselarasan strategi TI dan bisnis penting diterapkan agar dapat meningkatkan efisiensi operasi, meningkatkan inovasi organisasi dan membangun sumber daya informasi yang strategis [11].

Penelitian yang dilakukan oleh peneliti terdahulu umumnya mengambil objek pada perusahaan berorientasi profit dan berada pada negara maju. Sementara pada level pendidikan, penelitian tentang keselarasan strategi TI dan bisnis masih jarang dilakukan, terutama pada Perguruan Tinggi. Padahal, pada era digital peran TI yang selaras dengan strategi TI sangat diperlukan. Penelitian yang dilakukan oleh Goni [12] membuktikan bahwa sebagian besar Institusi Pendidikan Tinggi tidak mementingkan strategi sistem informasi pada awal implementasi. Institusi masih menggunakan metode manual untuk menilai kinerja keberlanjutan. Akibatnya, pengambilan keputusan keberlanjutan sulit dilakukan karena tidak memiliki data pasti dan pihak manajemen tidak dapat mengevaluasi nilai saing berkesinambungan

Universitas XYZ adalah Universitas Swasta yang telah mengadopsi TI kedalam bisnisnya sejak awal kampus tersebut berdiri pada tahun 2008 silam. Pada tahun 2014, Universitas XYZ mencanangkan program SmartXYZ sebagai bentuk komitmen untuk mencapai tujuan Universitas XYZ menjadi Smart Campus dalam roadmap Universitas XYZ 2014-2018. SmartXYZ dicanangkan sebagai upaya untuk menjadikan TI sebagai penopang strategi bisnis Universitas XYZ yang mencakup bidang akademik, penelitian, pengabdian, keagamaan, administrasi, manajemen, dan kepegawaian yang tersistem secara full online yang dirangkum dalam satu web portal SmartXYZ.

Dalam wawancara langsung yang dilakukan oleh penulis dengan Asisten Rektor Universitas XYZ, dikatakan bahwa hingga batas waktu target milestone 2018 SmartXYZ hanya mampu menjawab 30\% dari keseluruhan target yang telah direncanakan. Diungkapkan bahwa sistem yang dibangun belum bisa mendukung isu-isu strategis dan terkadang melahirkan hambatan baru dari penerapan sistem tersebut. Sebagai contoh ketika pihak manajemen tingkat atas ingin mengetahui performance dosen, maka harus mengunduh data berformat excel dari dalam sistem terlebih dahulu dan melakukan analisis manual sesuai data yang diperlukan. Begitu juga dalam kegiatan operasional, seperti pada data-data laporan keuangan yang sebagian masih diolah secara konvensional menggunakan office software sehingga data yang telah diolah tidak tersimpan secara terpusat dalam satu penyimpanan.

Hal tersebut merefleksikan bahwa Universitas XYZ telah menemui hambatan-hambatan terkait upaya penyelarasan strategi TI dan bisnis. Hambatan tersebut berdampak pada tidak tercapainya target program SmartXYZ untuk menjadikan TI sebagai penopang tujuan strategi bisnis untuk menjadikan Universitas XYZ sebagai Smart Campus sesuai milestone yang telah direncanakan. Sementara itu, komitmen Universitas XYZ untuk menjadi Smart Campus tetap terus diupayakan dalam lima tahun ke depan dengan harapan target Universitas XYZ untuk menjadi Smart Campus dapat tercapai. Oleh sebab itu, agar kesalahan tidak terulang kembali dalam mewujudkan Universitas XYZ sebagai Smart Campus, perlu dilakukan penelitian untuk mengidentifikasi faktor-faktor apa saja yang mempengaruhi keselarasan strategi TI dan bisnis pada Universitas XYZ agar strategi bisnis Universitas XYZ untuk menjadi Smart Campus dapat tercapai.

Berdasarkan latar belakang masalah yang telah dijelaskan sebelumnya, dapat disimpulkan bahwa strategi TI dan bisnis Universitas XYZ untuk mewujudkan Smart Campus belum selaras. Sementara itu, program smartXYZ yang dicanangkan demi mencapai tujuan Universitas XYZ sebagai Smart Campus masih tetap dijalankan dalam lima tahun ke depan. Oleh sebab itu perlu dilakukan penelitian untuk mengidentifikasi faktor-faktor apa saja yang mempengaruhi keselarasan strategi TI dan bisnis Universitas XYZ dalam upaya mewujudkan Smart Campus. 


\section{Metode Penelitian}

Seperti yang terlihat pada Gambar 2.1, penelitian ini diawali dengan melakukan identifikasi masalah dengan cara mengumpulkan data-data primer pada objek penelitian. Selanjutnya penulis melakukan studi literatur terhadap beberapa penelitian terdahulu yang relevan terhadap kondisi objek penelitian untuk menentukan perumusan masalah yang akan menjadi fokus dalam penelitian ini. Selanjutnya penulis membangun beberapa hipotesis berdasarkan studi literatur teori keselarasan strategi TI dan bisnis dari beberapa ahli, dari hipotesis-hipotesis tersebut diformulasikan menjadi sebuah model penelitian. Model penelitian tersebut berguna untuk parameter penyusunan kuesioner yang akan diujikan kepada responden.

Penelitian dilanjutkan dengan menentukan indikator-indikator dari setiap variabel yang berguna untuk parameter menyusun kuesioner. Lalu menyusun kuesioner yang mempunyai 6 tingkatan skala likert yang akan digunakan sebagai alat untuk mengumpulkan data dari responden. Sebelum melakukan survey menyeluruh, penulis melakukan uji validitas dan reliabilitas butir pertanyaan yang ada pada kuesioner dengan cara melakukan survey kecil terlebih dahulu. Jika pertanyaan tidak memenuhi syarat maka diganti atau dihilangkan dari butir kuesioner. Lalu dilanjutkan dengan melakukan survey menyeluruh terhadap semua responden. Setelah data dari responden terkumpul, hasil jawaban responden tersebut diolah menggunakan SmartPLS. Tahapan akhir pada penelitian ini adalah menghasilkan kesimpulan yang akan menjawab faktor-faktor apa saja yang berpengaruh signifikan terhadap keselarasan strategi TI dan bisnis pada Universitas XYZ.

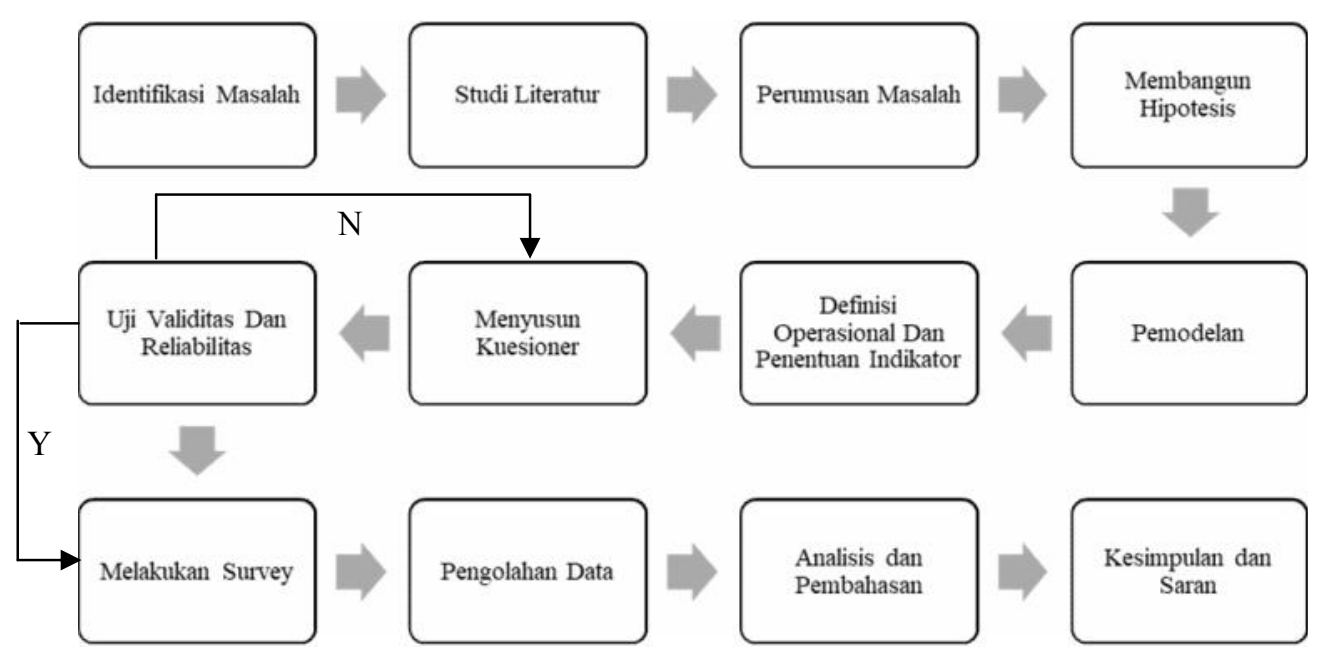

Gambar 2.1. Tahapan penelitian

\subsection{Objek Penelitian}

Objek penelitian adalah hal yang menjadi sasaran penelitian [13]. Lebih lanjut lagi objek penelitian dapat diartikan sebagai himpunan elemen yang dapat berupa orang, organisasi atau barang yang akan diteliti [14]. Kemudian dipertegas bahwa objek penelitian adalah pokok persoalan yang hendak diteliti untuk mendapatkan data secara lebih terarah [15]. Adapun Objek penelitian dalam penelitian ini adalah meliputi: (1) Pihak manajemen bisnis Universitas XYZ (2) strategi bisnis Universitas XYZ (3) Pihak UPTK Teknologi Informasi Universitas XYZ (4) Strategi TI Universitas XYZ.

\subsection{Populasi dan Sampel}

Populasi adalah kumpulan individu atau objek penelitian yang memiliki kualitas-kualitas serta ciri-ciri yang telah ditetapkan. Berdasarkan kualitas dan ciri tersebut, populasi dapat dipahami sebagai sekelompok individu atau objek pengamatan yang minimal memiliki satu persamaan karakteristik [16]. Populasi juga dapat diartikan seluruh data yang menjadi perhatian 
kita dalam suatu ruang lingkup dan waktu yang kita tentukan [17]. Sedangkan menurut Sukmadinata [18] mengemukakan bahwa populasi adalah kelompok besar dan wilayah yang menjadi lingkup penelitian kita.

Sampel adalah sebagian dari populasi yang memiliki karakteristik yang relatif sama dan dianggap dapat mewakili populasi [19]. Sedangkan menurut Sugiyono [20], sampel adalah bagian dari jumlah dan karakteristik yang dimiliki oleh populasi. Adapun metoda sampling yang digunakan adalah purposive sampling, yaitu teknik pengambilan sampel dengan memperhatikan pertimbangan-pertimbangan yang dibuat oleh peneliti (kualitatif subjektif). Pemilihan sampel secara kualitatif subjektif dipilih secara selektif oleh peneliti agar mendapatkan responden yang tepat dan memenuhi kualifikasi sehingga mendapatkan data yang valid dan menghindari anomali data.

Sesuai uraian diatas maka populasi dalam penelitian ini adalah pihak manajemen puncak, manajemen menengah, dan manajemen operasional pada Universitas XYZ. Sampel pada penelitian ini kurang lebih sejumlah 70 responden meliputi Rektorat beserta jajarannya, Kepala Biro beserta Jajarannya, Kepala Bagian Perencanaan dan Bisnis, Kepala UPT Teknologi Informasi, Administrator Sistem Informasi, Administrator Jaringan, Kepala Perpustakaan, Jajaran Dekan hingga Jajaran Kepala program studi pada Universitas XYZ.

\section{Hasil dan Pembahasan}

\subsection{Pengembangan hipotesis dan model penelitian}

Beberapa peneliti terdahulu telah mengidentifikasi beberapa faktor yang mempengaruhi keselarasan antara strategi IT dan bisnis, seperti eksekutif senior pada sebuah organisasi yang memiliki dukungan tinggi terhadap TI menempati urutan pertama dalam faktor yang mendukung keselarasan strategi TI dan bisnis [4]. Terbukti bahwa manajemen puncak yang berkomitmen tinggi terhadap TI adalah faktor utama yang mempengaruhi keselarasan [21]. Komitmen CEO terhadap TI berpengaruh positif terhadap keselarasan [22]. Pendapat lain yang serupa menyatakan bahwa sebagian besar perusahaan dengan kepemimpinan yang kuat dan dapat berkolaborasi dengan TI memiliki tingkat keselarasan strategi TI dan bisnis yang tinggi [23]. Pada Perguruan Tinggi, manajemen puncak adalah Rektor beserta jajarannya. Komitmen Rektor beserta jajaran didalam sebuah Perguruan Tinggi sangatlah penting. Hal ini berkaitan dengan regulasi, birokrasi, dan alokasi sumber daya baik berupa tenaga maupun dana dari sisi TI maupun bisnis seluruhnya diatur oleh Rektor beserta jajarannya. Oleh karena itu komitmen Rektor beserta jajaran sangatlah penting dalam keselarasan strategi TI dan bisnis pada sebuah Perguruan Tinggi. H1 : Komitmen manajemen puncak berpengaruh positif terhadap keselarasan TI dan bisnis.

Faktor selanjutnya adalah tenaga TI eksternal, Hasil Evaluasi Diri dalam Renstra Pengembangan Universitas XYZ 2014-2018 menyebutkan bahwa Universitas XYZ memiliki keterbatasan dalam jumlah dan kompetensi staf operasional TI yang belum optimal. Dengan demikian, terbatasnya jumlah sumber daya manusia pada UPT Teknologi Informasi menjadi salah satu kendala dalam menjalankan strategi TI di Universitas XYZ. Untuk mengatasi hal tersebut, Universitas XYZ bermitra dengan Universitas Muhammadiyah lain yang tersebar diberbagai Provinsi diseluruh Indonesia dan juga memiliki pihak eksternal seperti vendor dan konsultan yang kompeten dalam bidang TI untuk membantu implementasi TI di Universitas XYZ. Hal ini senada dengan penelitian [22], bahwa tenaga eksternal TI adalah salah satu faktor yang mempengaruhi keselarasan strategi TI dan bisnis. H2 : Penggunaan tenaga TI eksternal berpengaruh positif terhadap keselarasan TI dan bisnis. 
Disamping tenaga TI eksternal, penelitian [24] menghasilkan kesimpulan bahwa keterampilan staf TI internal merupakan faktor yang juga harus disertakan sebagai faktor keselarasan strategi TI dan bisnis. Staf bagian TI yang menguasai pemanfaatan berbagai bentuk teknologi, memiliki wawasan dan pengetahuan tentang manajemen maupun bisnis, serta mampu bekerja secara kooperatif dengan siapapun dan dari bagian manapun dalam organisasi, akan mampu membantu organisasi dalam memberi tanggapan terhadap berbagai perubahan lingkungan eksternal perusahaan [24]. penelitian [4] juga mengidentifikasi hal tersebut sebagai faktor yang mendorong terwujudnya keselarasan TI dan bisnis. Universitas XYZ melakukan pengembangan diri dan pengetahuan terhadap staf TI internal Universitas XYZ dengan upaya memfasilitasi mereka dengan pelatihan-pelatihan terkait Teknologi Informasi yang diadakan didalam maupun diluar Kota Pekanbaru. Wawasan dan pengetahuan yang berumber dari bahan bacaan seperti jurnal dan majalah Teknologi Informasi juga disediakan oleh Universitas XYZ agar staf TI up to date terhadap isu-isu Teknologi Informasi terbaru dan dengan wawasan dan pengetahuan tersebut, maka staf TI memiliki pemahaman yang mendalam mengenai kebutuhan dan harapan sisi bisnis terhadap TI dan dapat mengakomodasikan kebutuhan tersebut dalam kegiatan penyusunan strategi TI pada Universitas XYZ. H3 : Kemampuan staf TI internal berpengaruh positif terhadap keselarasan TI dan bisnis.

Universitas XYZ memiliki tiga (3) lokasi gedung kampus yang tersebar di Provinsi Riau dan terletak berjauhan. Oleh sebab itu fleksibilatas infrastruktur TI sangatlah penting untuk mendukung dan memastikan Teknologi Informasi berjalan dengan baik pada seluruh bagian Universitas XYZ. Hasil penelitian [25] menyimpulkan bahwa fleksibilitas infrastruktur TI dibutuhkan oleh perusahaan agar memungkinkan strategi TI dengan cepat dan mudah dibawa ke kondisi yang sesuai dengan tuntutan bisnis yang baru, sehingga modifikasi terhadap berbagai aplikasi yang berbasis TI dapat dengan mudah dilaksanakan sesuai dengan proses yang ditentukan oleh strategi bisnis. Bahwa karakteristik fleksibilitas infrastruktur TI dapat dinilai dari konektivitas, kompatibilitas dan modularitas yang dimiliki oleh infrastruktur TI tersebut [26]. Hasil analisis [27] juga menyimpulkan bahwa kondisi infrastruktur TI perusahaan dengan konektivitas, kompatibilitas dan modularitas yang tinggi akan membawa perusahaan ke arah kinerja yang meningkat. H4 : Fleksibilitas infrastruktur TI berpengaruh positif terhadap keselarasan TI dan bisnis.

Kemampuan komunikasi dalam hal menyelaraskan pengetahuan antara sisi bisnis dan sisi TI dipandang sebagai salah satu faktor yang sangat penting dalam usaha menyelaraskan strategi TI dan bisnis. Kedekatan hubungan antara eksekutif bisnis dan TI memungkinkan mereka untuk bekerja sama untuk memahami kebutuhan teknologi dan bisnis dari organisasinya. Sebagai hasil dari hubungan ini adalah kemampuan TI bertambah dan nilai bisnis akan semakin meningkat. Hal ini juga akan menjamin bahwa integrasi TI dan strategi bisnis dan sukses. Penelitian membuktikan bahwa berbagi pengetahuan antara divisi bisnis dan divisi TI berpengaruh positif terhadap keselarasan [30]. Hal tersebut juga didukung oleh [4] bahwa bagian TI mengetahui bisnis dan keterkaitan antara bagian bisnis dengan TI berpengaruh positif terhadap keselarasan strategi TI dan bisnis. Manajemen sistem informasi yang mengetahui tentang bisnis berpengaruh positif terhadap keselarasan [22]. Sementara itu argumen [31] mendukung bahwa perusahaan dengan eksekutif TI dan bisnis yang saling berbagi pengetahuan sebagian besar dapat mencapai keselarasan strategi TI dan bisnis. H5 : Komunikasi pengetahuan antara eksekutif TI dan eksekutif bisnis berpengaruh positif terhadap keselarasan TI dan bisnis. 
Dari hasil observasi, studi literatur, penelitian terdahulu, dan rangkuman teori yang digunakan maka penulis mengajukan 5 hipotesis yang digunakan untuk membangun sebuah model penelitian seperti yang terlihat pada Gambar 3.1.

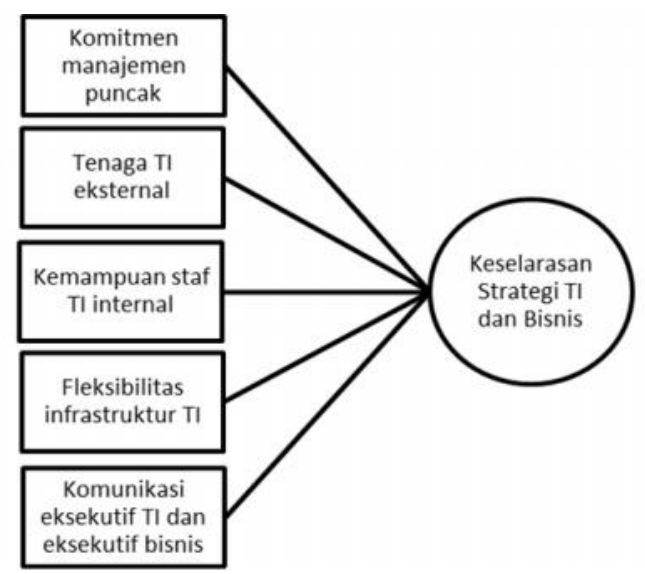

Gambar 3.1. Model penelitian

\subsection{Uji validitas dan reliabilitas}

Uji validitas digunakan untuk mengukur valid atau tidaknya suatu kuesioner dalam mengukur suatu konstruk, dan apakah dimensi-dimensi yang diukur secara sungguh-sungguh mampu menjadi item-item dalam pengukuran [32]. Reliabilitas menunjukkan konsistensi dan stabilitas dari suatu skor skala pengukuran [33]. Suatu data dinyatakan reliabel apabila dua atau lebih peneliti dalam objek yang sama menghasilkan data yang sama, atau sekelompok data bila dipecah menjadi dua menunjukkan data yang tidak berbeda [34]. Uji reliabilitas dapat dilihat dari nilai Cronbach's Alpha dan nilai composite reliability. Untuk dapat dikatakan suatu item pertanyaan reliabel, maka nilai Cronbach's Alpha harus > 0,6 [32].

\subsection{Uji Validitas}

Pengujian validitas dilakukan dengan menghitung korelasi antara skor item instrument dengan skor total. Nilai koefisien korelasi antara skor setiap item dengan skor total dihitung dengan analisis corrected item-total correlation, suatu instrumen penelitian dikatakan valid apabila memenuhi kriteria sebagai berikut:

1. Bila $r_{\text {hitung }}>r_{\text {tabel }}$, maka dinyatakan valid.

2. Bila $\mathrm{r}_{\text {hitung }}<\mathrm{r}_{\text {tabel }}$, maka dinyatakan tidak valid.

Tabel 3.1 Hasil Uji Validitas

\begin{tabular}{|l|l|r|r|c|}
\hline \multicolumn{1}{|c|}{ Variabel } & Item & r hitung & \multicolumn{1}{c|}{ r tabel } & Keterangan \\
\hline \multirow{4}{*}{ Dukungan Manajemen Puncak (MP) } & MP1 & 0,724 & 0,361 & Valid \\
\cline { 2 - 5 } & MP2 & 0,748 & 0,361 & Valid \\
\cline { 2 - 5 } & MP3 & 0,641 & 0,361 & Valid \\
\cline { 2 - 5 } & MP4 & 0,836 & 0,361 & Valid \\
\hline \multirow{5}{*}{ Tenaga TI Eksternal (TIE) } & TIE1 & 0,251 & 0,361 & Tidak Valid \\
\cline { 2 - 5 } & TIE2 & 0,496 & 0,361 & Valid \\
\cline { 2 - 5 } & TIE3 & 0,673 & 0,361 & Valid \\
\cline { 2 - 5 } & TIE4 & 0,583 & 0,361 & Valid \\
\cline { 2 - 5 } & TIE5 & 0,291 & 0,361 & Tidak Valid \\
\hline \multirow{3}{*}{ Staf TI Internal (STI) } & STI1 & 0,807 & 0,361 & Valid \\
\cline { 2 - 5 } & STI2 & 0,424 & 0,361 & Valid \\
\cline { 2 - 5 } & STI3 & 0,807 & 0,361 & Valid \\
\hline
\end{tabular}




\begin{tabular}{|l|l|r|r|r|}
\multirow{4}{*}{ Fleksibilitas Infrastruktur TI (FTI) } & FTI1 & 0,909 & 0,361 & Valid \\
\cline { 2 - 5 } & FTI2 & 0,877 & 0,361 & Valid \\
\cline { 2 - 5 } & FTI3 & 0,622 & 0,361 & Valid \\
\hline \multirow{4}{*}{ Komunikasi TI dan Bisnis (KTI) } & KTI1 & 0,869 & 0,361 & Valid \\
\cline { 2 - 5 } & KTI2 & 0,470 & 0,361 & Valid \\
\cline { 2 - 5 } & KTI3 & 0,683 & 0,361 & Valid \\
\cline { 2 - 5 } & KTI4 & 0,913 & 0,361 & Valid \\
\hline \multirow{3}{*}{ Keselarasan IT dengan Bisnis (KTB) } & KTB1 & 0,392 & 0,361 & Valid \\
\cline { 2 - 5 } & KTB2 & 0,547 & 0,361 & Valid \\
\cline { 2 - 5 } & KTB3 & 0,706 & 0,361 & Valid \\
\cline { 2 - 5 } & KTB4 & 0,692 & 0,361 & Valid \\
\hline
\end{tabular}

Pada Tabel 3.1 menunjukkan hasil uji validitas untuk seluruh indikator bahwa nilai $r_{\text {hitung }}$ semua variabel lebih besar dibanding nilai $r_{\text {tabel }}$ Kecuali untuk indikator variabel TIE pada TIE1 dan TIE5. Karena indikator TIE1 dan TIE5 tersebut tidak valid, maka butir pertanyaan pada indikator tersebut tidak digunakan lagi pada kuesioner untuk survey menyeluruh. Dengan begitu, maka pada kuesioner yang digunakan pada survey menyeluruh indikator TIE1 = TIE2, TIE2 adalah TIE3, TIE3 adalah TIE4.

\subsection{Uji Reliabilitas}

Suatu kuesioner dikatakan handal atau reliable jika jawaban seseorang terhadap pertanyaan adalah konsisten atau stabil dari waktu ke waktu. Teknik yang digunakan untuk mengukur tingkat reliabilitas adalah cronbach alpha dengan cara membandingkan nilai alpha dengan standarnya. Koefisien cronbach alpha yang lebih dari 0,60 menunjukkan keandalan (reliabilitas) instrumen. Selain itu, yang semakin mendekati 1 menunjukkan semakin tinggi konsistensi internal reliabilitasnya.

Tabel 3.2 Hasil Uji Reliabilitas

\begin{tabular}{lccc}
\hline \multicolumn{1}{c}{ Variabel } & $\begin{array}{c}\text { Cronbach's } \\
\text { Alpha }\end{array}$ & $\begin{array}{c}\text { Standar } \\
\text { Reliabilitas }\end{array}$ & Kesimpulan \\
\hline Dukungan Manajemen Puncak (MP) & 0,866 & 0,6 & Reliabel \\
Tenaga TI Eksternal (TIE) & 0,673 & 0,6 & Reliabel \\
Staf TI Internal (STI) & 0,806 & 0,6 & Reliabel \\
Fleksibilitas Infrastruktur TI (FTI) & 0,895 & 0,6 & Reliabel \\
Komunikasi TI dan Bisnis (KTI) & 0,871 & 0,6 & Reliabel \\
Keselarasan IT dengan Bisnis (KTB) & 0,759 & 0,6 & Reliabel \\
\hline
\end{tabular}

Tabel 3.2 menunjukkan nilai cronbach alpha semua variabel lebih besar dari 0,60 sehingga dapat disimpulkan indikator atau kuesioner yang digunakan untuk semua variabel dapat dipercaya sebagai alat ukur variabel (reliabel).

\subsection{Analisis Partial Least Square (PLS)}

Dalam penelitian ini analisis data menggunakan pendekatan Partial Least Square (PLS) yang menggunakan software smartPLS 3.0. Partial Least Square (PLS) adalah model persamaan struktural (SEM) yang berbasis komponen variance. Pendekatan PLS adalah distributions free (tidak menggunakan data terdistribusi tertentu, dapat berupa nominal, kategori, ordinal, interval maupun rasio). Selain itu PLS juga dapat digunakan untuk mengukur sampel yang jumlahnya kecil. Berikut ini tahap-tahap menggunakan pendekatan Least Square (PLS) dengan menggunakan software smartPLS.

\subsection{Menilai Outer Model atau Measurement Model}

Terdapat tiga kriteria di dalam penggunaan teknik analisis data dengan SmartPLS untuk menilai outer model yaitu Convergent Validity, Discriminant Validity dan Composite 
Reliability. Berikut adalah Gambar 3.2 menunjukkan nilai outer loading untuk masing-masing indikator yang digunakan pada penelitian ini.

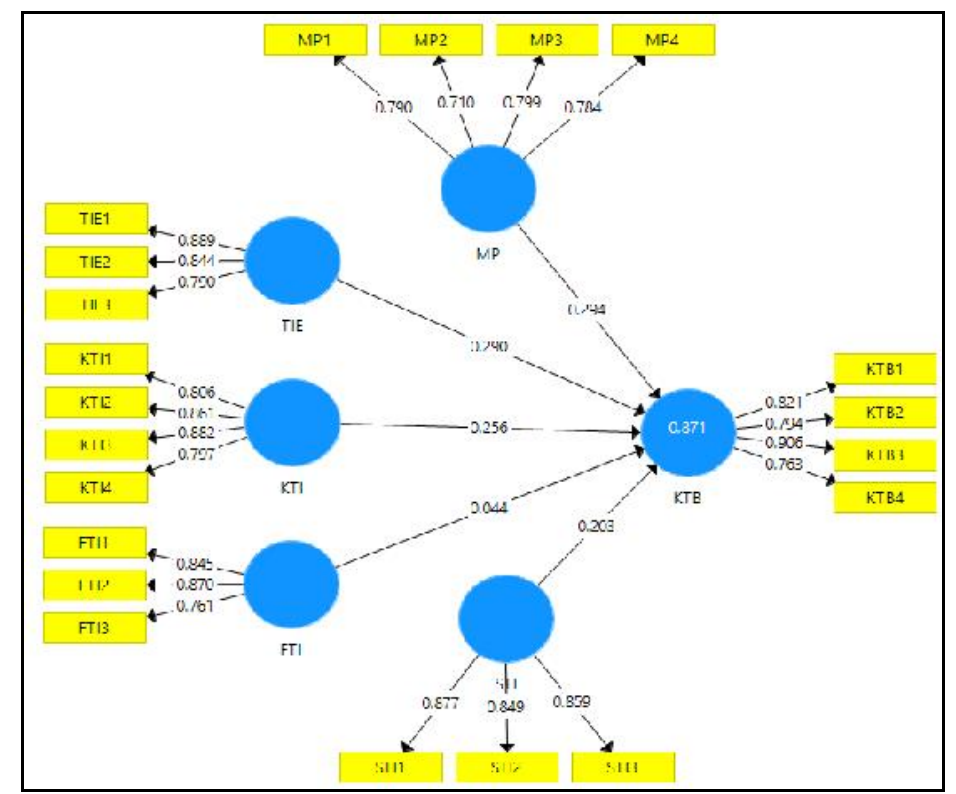

Gambar 3.2 Outer Model.

\subsection{Convergent validity}

Convergent validity dari model pengukuran dengan refleksif indikator dinilai berdasarkan korelasi antara item score/component score yang diestimasi dengan software PLS. Ukuran refleksif individual dikatakan tinggi jika berkorelasi lebih dari 0,70 dengan konstruk yang diukur. Namun menurut [35] untuk penelitian tahap awal dari pengembangan skala pengukuran nilai loading 0,5 sampai 0,6 dianggap cukup memadai. Dalam penelitian ini akan digunakan batas loading factor sebesar 0,70 .

Tabel 3.3 Outer loading (Measurement Model)

\begin{tabular}{|c|c|}
\hline INDIKATOR & OUTER LOADING \\
\hline FTI1 & 0.8447 \\
\hline FTI2 & 0.8703 \\
\hline FTI3 & 0.7611 \\
\hline KTB1 & 0.8209 \\
\hline KTB2 & 0.7938 \\
\hline KTB3 & 0.9064 \\
\hline KTB4 & 0.7627 \\
\hline KTI1 & 0.8060 \\
\hline KTI2 & 0.8615 \\
\hline KTI3 & 0.8824 \\
\hline KTI4 & 0.7969 \\
\hline MP1 & 0.7898 \\
\hline MP2 & 0.7102 \\
\hline MP3 & 0.7993 \\
\hline MP4 & 0.7839 \\
\hline STI1 & 0.8773 \\
\hline STI2 & 0.8494 \\
\hline STI3 & 0.8591 \\
\hline TIE1 & 0.8886 \\
\hline TIE2 & 0.8437 \\
\hline TIE3 & 0.7896 \\
\hline
\end{tabular}


Dari tabel 3.3 diperoleh pengujian outer loading untuk seluruh indikator memiliki nilai lebih besar daripada 0.7. sehingga Ukuran refleksif individual dikatakan memenuhi syarat.

\subsection{Discriminant Validity}

Discriminant validity dilakukan untuk memastikan bahwa setiap konsep dari masing variabel laten berbeda dengan variabel lainnya. Model mempunyai discriminant validity yang baik jika setiap nilai loading dari setiap indikator dari sebuah variabel laten memiliki nilai loading yang paling besar dengan nilai loading lain terhadap variabel laten lainnya. Hasil pengujian discriminant validity diperoleh sebagai berikut:

Tabel 3.4 Nilai Discriminant Validity (Cross Loading)

\begin{tabular}{|c|c|c|c|c|c|c|}
\hline INDIKATOR & FTI & KTB & KTI & MP & STI & TIE \\
\hline FTI1 & 0.8447 & 0.1665 & 0.1388 & 0.1833 & 0.1659 & 0.1854 \\
\hline FTI2 & 0.8703 & 0.1329 & 0.0901 & 0.0972 & 0.0249 & -0.0241 \\
\hline FTI3 & 0.7611 & 0.0928 & 0.0691 & 0.0278 & 0.0539 & 0.0008 \\
\hline KTB1 & 0.0940 & 0.8209 & 0.7618 & 0.7238 & 0.5081 & 0.6955 \\
\hline KTB2 & 0.0952 & 0.7938 & 0.6282 & 0.6967 & 0.6056 & 0.7109 \\
\hline KTB3 & 0.0667 & 0.9064 & 0.7287 & 0.7772 & 0.6665 & 0.8219 \\
\hline KTB4 & 0.3116 & 0.7627 & 0.6080 & 0.6512 & 0.5273 & 0.6259 \\
\hline KTI1 & 0.1874 & 0.6909 & 0.8060 & 0.6345 & 0.4074 & 0.5580 \\
\hline KTI2 & 0.0323 & 0.7285 & 0.8615 & 0.6819 & 0.5020 & 0.7425 \\
\hline KTI3 & -0.0279 & 0.7250 & 0.8824 & 0.6654 & 0.4551 & 0.7393 \\
\hline KTI4 & 0.2572 & 0.6325 & 0.7969 & 0.6344 & 0.3593 & 0.6579 \\
\hline MP1 & 0.1566 & 0.7147 & 0.6743 & 0.7898 & 0.5049 & 0.7353 \\
\hline MP2 & 0.1244 & 0.5506 & 0.4617 & 0.7102 & 0.4276 & 0.5333 \\
\hline MP3 & 0.0148 & 0.6386 & 0.5613 & 0.7993 & 0.4248 & 0.6363 \\
\hline STI1 & 0.1323 & 0.7469 & 0.6801 & 0.7839 & 0.5445 & 0.6416 \\
\hline STI2 & 0.0560 & 0.4463 & 0.2450 & 0.3922 & 0.8773 & 0.3870 \\
\hline STI3 & 0.1468 & 0.7942 & 0.6824 & 0.6966 & 0.8494 & 0.6979 \\
\hline TIE1 & 0.0225 & 0.4089 & 0.2004 & 0.3720 & 0.8591 & 0.3781 \\
\hline TIE2 & 0.0203 & 0.7693 & 0.7096 & 0.7083 & 0.6310 & 0.8886 \\
\hline TIE3 & 0.1758 & 0.7115 & 0.6286 & 0.6633 & 0.4720 & 0.7896 \\
\hline
\end{tabular}

Dari tabel 3.4 dapat dilihat bahwa beberapa nilai loading factor untuk setiap indikator dari masing-masing variabel laten tidak ada yang memiliki nilai loading factor yang tidak paling besar dibanding nilai loading jika dihubungkan dengan variabel laten lainnya. Hal ini berarti bahwa setiap variabel laten telah memiliki discriminant validity yang baik dimana beberapa variabel laten tidak memiliki pengukur yang berkorelasi tinggi dengan konstruk lainnya.

\subsection{Composite Reliability dan Average Variance Extracted (AVE)}

Kriteria validity dan reliabilitas juga dapat dilihat dari nilai reliabilitas suatu konstruk dan nilai Average Variance Extracted (AVE) dari masing-masing konstruk. Konstruk dikatakan memiliki reliabilitas yang tinggi jika nilainya 0,70 dan AVE berada diatas 0,50 . Pada tabel 3.5 akan disajikan nilai Composite Reliability dan AVE untuk seluruh variabel.

Tabel 3.5 Cronbach's Alpha, Composite Reliability dan Average Variance Extracted

\begin{tabular}{|c|c|c|c|}
\hline VARIABEL & Cronbach's Alpha & Composite Reliability & AVE \\
\hline FTI & $\mathbf{0 . 7 7 6 9}$ & $\mathbf{0 . 8 6 5 9}$ & $\mathbf{0 . 6 8 3 4}$ \\
\hline KTB & $\mathbf{0 . 8 3 9 0}$ & $\mathbf{0 . 8 9 2 9}$ & $\mathbf{0 . 6 7 6 8}$ \\
\hline KTI & $\mathbf{0 . 8 5 7 4}$ & $\mathbf{0 . 9 0 3 6}$ & $\mathbf{0 . 7 0 1 4}$ \\
\hline
\end{tabular}




\begin{tabular}{|c|c|c|c|}
\hline MP & $\mathbf{0 . 7 7 4 4}$ & $\mathbf{0 . 8 5 4 5}$ & $\mathbf{0 . 5 9 5 4}$ \\
\hline STI & $\mathbf{0 . 8 4 7 1}$ & $\mathbf{0 . 8 9 6 6}$ & $\mathbf{0 . 7 4 3 1}$ \\
\hline TIE & $\mathbf{0 . 7 9 2 6}$ & $\mathbf{0 . 8 7 9 1}$ & $\mathbf{0 . 7 0 8 3}$ \\
\hline
\end{tabular}

Berdasarkan tabel 3.5 dapat disimpulkan bahwa semua konstruk memenuhi kriteria reliabel. Hal ini ditunjukkan dengan nilai Cronbach's Alpha composite reliability di atas 0,70 dan AVE diatas 0,50 sebagaimana kriteria yang direkomendasikan.

\subsection{Koefisien Determinasi (R-Squares)}

Dalam menilai model struktural dengan PLS, dimulai dengan melihat nilai R-Squares untuk setiap variabel laten endogen sebagai kekuatan prediksi dari model struktural. Perubahan nilai R-Squares dapat digunakan untuk menjelaskan pengaruh variabel laten eksogen tertentu terhadap variabel laten endogen apakah mempunyai pengaruh yang substantif. Nilai R-Squares 0,75 (kuat), 0,50 (moderate) dan 0,25 (lemah). Hasil dari PLS R-Squares merepresentasi jumlah variance dari konstruk yang dijelaskan oleh model [32].

Tabel 3.6 Model Struktural (Inner Model) dan GoF

\begin{tabular}{|c|c|c|}
\hline VARIABEL & R Square & Adjusted R Square \\
\hline KTB & 0.8707 & 0.8593 \\
\hline
\end{tabular}

Dari tabel didapatkan nilai R-Squares sebesar 0.8707 artinya $87.07 \%$ perubahan nilai KTB dapat dijelaskan oleh variabel bebas dalam penelitian.

\subsection{Pengujian Signifikansi dan Pengujian Hipotesis}

Dalam PLS pengujian secara statistik setiap hubungan yang dihipotesiskan dilakukan dengan menggunakan simulasi. Dalam hal ini dilakukan metode bootstrap terhadap sampel. Pengujian dengan bootstrap juga dimaksudkan untuk meminimalkan masalah ketidaknormalan data penelitian. Parameter signifikansi yang diestimasi memberikan informasi yang sangat berguna mengenai hubungan antara variabel-variabel penelitian.

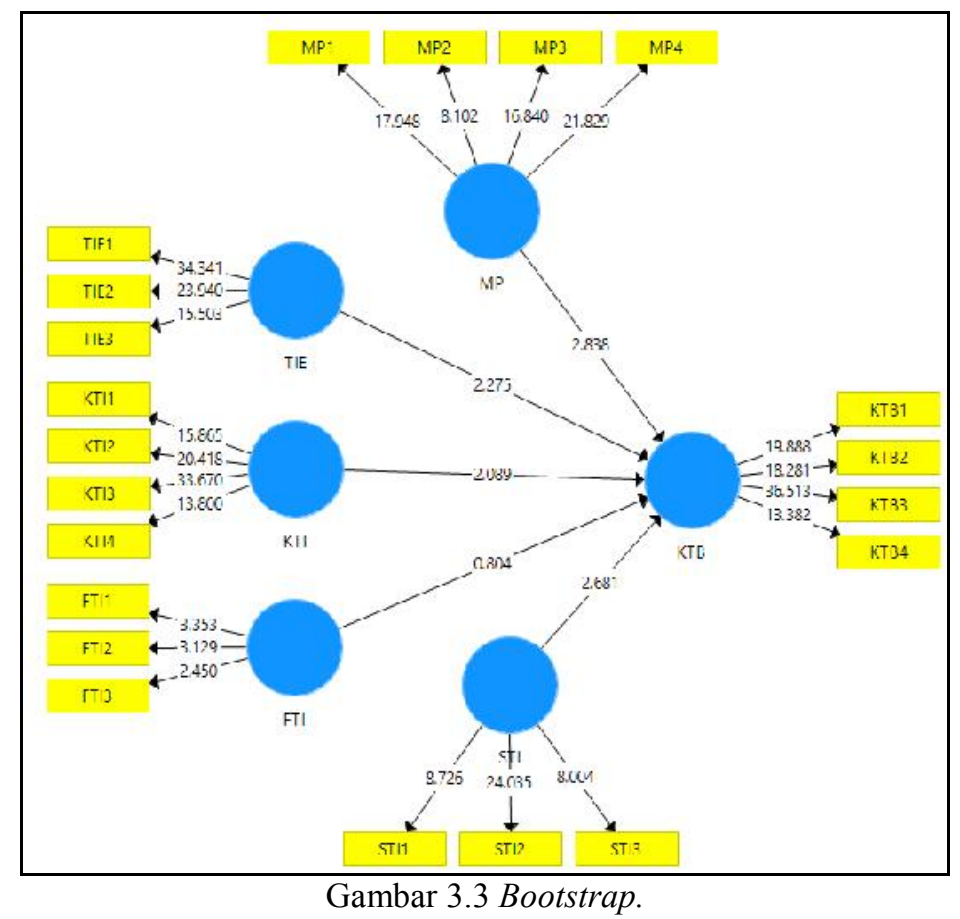


Hasil pengujian dengan bootstrapping dari analisis PLS dapat dilihat pada output result for inner weight yang disajikan pada gambar model struktural. Berdasarkan Gambar 3.3, berikut akan dijelaskan pengujian masing-masing hipotesis

\subsection{Pengaruh Langsung (Direct Effect)}

Model struktural (inner model) merupakan model struktural untuk memprediksi hubungan kausalitas antar variabel laten [32] Untuk memprediksi adanya hubungan kausalitas dalam SEM-PLS dengan menggunakan SmartPLS 3.0 sebagai berikut :

Tabel 3.7 Result For Inner Weights

\begin{tabular}{|c|c|c|c|c|c|}
\hline VARIABEL & $\begin{array}{c}\text { Sampel } \\
\text { Asli (O) }\end{array}$ & $\begin{array}{c}\text { Rata-rata } \\
\text { Sampel (M) }\end{array}$ & $\begin{array}{c}\text { Standar Deviasi } \\
\text { (STDEV) }\end{array}$ & $\begin{array}{c}\text { T Statistik } \\
\text { (O/STDEV) }\end{array}$ & P Values \\
\hline FTI -> KTB & 0.0443 & 0.0477 & 0.0552 & 0.8035 & $\mathbf{0 . 4 2 2 0}$ \\
\hline KTI -> KTB & 0.2561 & 0.2465 & 0.1226 & 2.0890 & $\mathbf{0 . 0 3 7 2}$ \\
\hline MP -> KTB & 0.2940 & 0.2915 & 0.1036 & 2.8376 & $\mathbf{0 . 0 0 4 7}$ \\
\hline STI -> KTB & 0.2031 & 0.2123 & 0.0758 & 2.6805 & $\mathbf{0 . 0 0 7 6}$ \\
\hline TIE -> KTB & 0.2901 & 0.2893 & 0.1275 & 2.2749 & $\mathbf{0 . 0 2 3 3}$ \\
\hline
\end{tabular}

Berdasarkan hasil analisis dapat dilakukan uji P-Value terhadap masing-masing variable bebas terhadap variable terikat KTB sebagai berikut:

1. Nilai $p$ value untuk variabel FTI adalah 0.4220 . Karena $p$ value $0.4220>0.05$ maka dapat disimpulkan bahwa FTI tidak berpengaruh signifikan terhadap KTB.

2. Nilai $p$ value untuk variabel KTI adalah 0.0372 . Karena $p$ value $<0.05$ maka dapat disimpulkan bahwa KTI berpengaruh signifikan terhadap KTB.

3. Nilai $p$ value untuk variabel MP adalah 0.0047. Karena $p$ value $0.0047<0.05$ maka dapat disimpulkan bahwa MP berpengaruh signifikan terhadap KTB.

4. Nilai $\mathrm{p}$ value untuk variabel STI 0.0076 . Karena $\mathrm{p}$ value $0.0076<0.05$ maka dapat disimpulkan bahwa STI berpengaruh signifikan terhadap KTB.

5. Nilai $p$ value untuk variabel TIE adalah 0.0233 . Karena $p$ value $0.0233<0.05$ maka dapat disimpulkan bahwa TIE berpengaruh signifikan terhadap KTB.

Tabel 3.8 Ringkasan dari hasil pengujian hipotesis

\begin{tabular}{|c|l|l|}
\hline No & \multicolumn{1}{|c|}{ Hipotesis } & Hasil \\
\hline H1 & $\begin{array}{l}\text { Komitmen manajemen puncak terhadap TI berpengaruh } \\
\text { positif terhadap keselarasan TI dan bisnis }\end{array}$ & Signifikan \\
\hline H2 & $\begin{array}{l}\text { Penggunaan tenaga TI eksternal berpengaruh positif } \\
\text { terhadap keselarasan TI dan bisnis }\end{array}$ & Signifikan \\
\hline H3 & $\begin{array}{l}\text { Kemampuan staf TI internal berpengaruh positif } \\
\text { terhadap keselarasan TI dan bisnis }\end{array}$ & Signifikan \\
\hline H4 & $\begin{array}{l}\text { Fleksibilitas infrastruktur TI berpengaruh positif } \\
\text { terhadap keselarasan TI dan bisnis }\end{array}$ & Tidak Signifikan \\
\hline H5 & $\begin{array}{l}\text { Komunikasi pengetahuan antara eksekutif TI dan } \\
\text { eksekutif bisnis berpengaruh positif terhadap keselarasan } \\
\text { TI dan bisnis }\end{array}$ & Signifikan \\
\hline
\end{tabular}

\section{Kesimpulan}

Penelitian ini bertujuan untuk mengetahui pengaruh komitmen manajemen puncak, penggunaan tenaga TI eksternal, kemampuan staf TI internal, fleksibilitas infrastruktur TI, dan komunikasi pengetahuan antara eksekutif TI dan eksekutif bisnis terhadap keselarasan TI dan bisnis pada Universitas XYZ. Berdasarkan pembahasan di atas, maka dapat disimpulkan bahwa komitmen manajemen puncak, penggunaan tenaga TI eksternal, kemampuan staf TI internal, dan komunikasi pengetahuan antara eksekutif TI dan eksekutif bisnis berpengaruh signifikan 
terhadap keselarasan TI dan bisnis pada Universitas XYZ. Sedangkan untuk fleksibilitas infrastruktur TI tidak berpengaruh signifikan terhadap keselarasan TI dan bisnis pada Universitas XYZ. Dengan meningkatkan kualitas dan intensitas faktor-faktor yang berpengaruh signifikan terhadap keselarasan TI dan bisnis tersebut diharapkan Universitas XYZ dapat menyelaraskan strategi TI sebagai penopang strategi bisnis Universitas XYZ untuk mencapai target menjadi Smart Campus melalui program SmartXYZ.

\section{Daftar Pustaka}

[1] Aasi, Parisa \& Rusu, Lazar \& Vieru, Dragos. (2017). The Role of Culture in IT Governance Five Focus Areas: A Literature Review. International Journal of IT/Business Alignment and Governance. 8. 42-61. 10.4018/IJITBAG.2017.

[2] ITGI. Board Briefing on IT Governance. 2nd Edition.IT Governance Institute, 2003.

[3] Papp, Raymond. (1999). Business-IT alignment: productivity paradox payoff?. Industrial Management \& Data Systems. 99. 367-373. 10.1108/02635579910301810.

[4] Luftman, J., N., Papp, R., dan Brier, T. Enablers and Inhibitors Of Business-It Alignment Enablers and Inhibitors Of Business-It Alignment. 1(March): 1-33, 1999.

[5] Boulianne, E. (2007). Revisiting Fit Between AIS Design and Performance With The Analyser Strategic Type. International Journal of Accounting Information Systems, 8, $1-6,2007$.

[6] Croteau, A.M., \& Raymond, L. Performance Outcomes of Strategic and IT Competencies Alignment. Journal of Information Technology, 19, 178-190, 2004.

[7] Sabherwal, R. and Chan Y. Alignment Between Business and IS Strategies: A Study of Prospectors, Analyzers, and Defenders, Information Systems Research, Vol 12, No. 1. Pp 11-33, 2001

[8] Peppard, J., Campbell, B. The Co-evolution of Business/Information Systems Strategic Alignment: An Exploratory Study, Manuscript for Journal of Information Technology, Special Issue. Strategic IT Alignment: Twenty Five Years, 2014.

[9] Luftman, J. N., \& Kempaiah, R. An update on Business IT alignment: A line has been drawn. MIS Quarterly Executive, 6(3), 165-177, 2007.

[10] CRUE, "Governance of information technology in higher education Spain: Spanish Association of University Rectors," CRUE, 2009. S. P. Masticola, "A simple estimate of the cost of software project

[11] James A. O'Brien , George Marakas, Introduction to Information Systems, McGrawHill, Inc., New York, NY, 2005

[12] Goni, AG Chofreh, M Mukhtar, S Sahran, SA Shukor, JJ Klemeš. Strategic alignment between sustainability and information systems: A case analysis in Malaysian Public Higher Education Institutions. Journal of cleaner production 168, 263-270, 2017.

[13] Kamus Besar Bahasa Indonesia, Edisi Keempat, 2008, Gramedia Pustaka Utama, Jakarta, 2008.

[14] J. Supranto M. A. (2000). Statistik Teori dan Aplikasi Jilid 1, Edisi Keenam. Erlangga, Jakarta.

[15] Anto, Dayan. 1986. Pengantar Metodologi Statistik Jilid d II. Jakarta:LP3 ES.

[16] Cooper, Donal R. dan Emory, William. Metode Penelitian Bisnis, alih bahasa Widyono Soecipto dan Uka Wikarya, Jilid 11, Jakarta: Erlangga, 1999.

[17] Margono. 2010. Metodologi Penelitian Pendidikan. Jakarta: Rineka Cipta.

[18] Sukmadinata, N.S. 2011. Metode Penelitian Pendidikan. Bandung: Remaja Rosadakarya. 
[19] Masri Singarimbun.1991. Metode Penelitian, Yogyakarta : LP3S.

[20] Sugiyono. (2011) Metode Penelitian Kuantitatif dan Kualitatif dan R \& D. Bandung: CV Alfabeta.

[21] Teo, T., S., H. dan Ang, J., S., K. Critical success factors in the alignment of IS plans with business plans. Int. J. Inf. Manage. 19(2): 173-185, 1999.

[22] Hussin, H., King, M., dan Cragg, P. IT alignment in small firms.Eur. J. Inf. Syst. 108127, 2002.

[23] Baker, "Leading Alignment," CIO Insight, vol. 1:45, pp. 19-20, 2004.

[24] S.H. Chung, R.K. Rainer, and B.R. Lewis, "The Impact of IT Infrastructure Flexibility on Strategic Alignment and Applications Implementation," Communication of the Association for Information Systems 11, 2003.

[25] Chan, Y. E., and Huff, S.L. Business Strategic Orientation, Information Systems Strategic Orientation, and Strategic Alignment, Information Systems Research (8:2), hal.125-150, 1997.

[26] Luftman, J. N. Applying the Strategic Alignment model,in J. Luftman (Ed.), Competing in the Information Age: Strategic Alignment in Practise, NY: Oxford University Press, hal. (43-69), 1996.

[27] N. Duncan, "Capturing Flexibility of Information Technology Infra-structure: A Study of Resource Characteristics and their Measure," Journal of Management Information Systems (12:2), 1995.

[28] Knoll, K. and Jarvenpaa, S.L. Information technology alignment or "fit" in highly turbulent environments: the concept of flexibility, Proceedings of the 1994 computer personnel research conference on Reinventing Information Systems, Alexandria, VA USA, hal. 1-14, 2005.

[29] Kanelis, P., and Paul, R.J. User Behaving Badly; Phenomena and Paradoxes from an Investigation into Information Systems Misfit, Journal of Organizational and End user Computing, IDEA Group Publishing (17:12), hal. 64 - 91, 2005.

[30] Chan, Y, E., Sabherwal, R., dan Thatcher, J, B. Antecedents and Outcomes of Strategic IS Alignment : An Empirical Investigation. 53(1): 27-47, 2006.

[31] Reich, B. H., Benbasat, I., Information, M., dan Division, S. Factors That Influence the Social Dimension of Alignment Between Business and Information Factors That Influence the Social, 1999.

[32] Ghozali, Imam, Structural Equation Modeling Metode Alternatif Dengan Partial Least Square (PLS) Edisi 3, Badan Penerbit Universitas Diponegoro. Semarang, 2011.

[33] Mudrajad Kuncoro, (2013). "Metode Riset untuk Bisnis dan Ekonomi” Edisi 4. Jakarta: Erlangga.

[34] Sugiyono. (2014). Metode Penelitian Pendidikan Pendekatan Kuantitatif, Kualitatif, dan R\&D. Bandung: Alfabeta.

[35] Chin, W. W. (1998). The Partial Least Squares Aproach to Structural Equation Modeling. Modern Methods for Business Research, 295, 336 